\title{
USE OF MONOCLONAL ANTIBODIES TO STUDY DIFFERENTIATION OF COLLETOTRICHUM INFECTION STRUCTURES
}

\author{
R.J. O'CONNELL' 1 , N.A. PAIN ${ }^{2}$, J.A. BAILEY', K. MENDGEN ${ }^{3}$ and \\ J.R. GREEN². \\ 'IACR-Long Ashton Research Station, Department of Agriculture, \\ University of Bristol, Long Ashton, Bristol BS18 9AF, UK. ${ }^{2}$ School of \\ Biological Sciences, The University of Birmingham, P.O. Box 363, \\ Birmingham B15 2TT, UK. ${ }^{3}$ Fakultät für Biologie, Universität Konstanz, \\ Postfach 5560, D-78434 Konstanz, Germany.
}

\section{Introduction}

Successful penetration and colonization of plant tissues by most fungal pathogens requires differentiation of specialised cell types or infection structures, e.g. germ tubes, appressoria, penetration hyphae, infection hyphae and haustoria. Each cell type is adapted to a particular role in the infection process, e.g. adhesion, contact-sensing, penetration and nutrient uptake [22,32]. Molecular genetic techniques, such as differential or subtractive hybridization and mutational analysis, are being used to identify genes involved in the morphogenesis and function of these infection structures. For example, many genes that are specifically expressed or up-regulated during the formation of appressoria by Colletotrichum, Magnaporthe and rust fungi have now been cloned $[7,8,23,24,27,29,55,69,76]$. Some of these genes have been sequenced and disrupted to determine their role in the infection process $[24,69]$. These approaches have so far been restricted to infection structures that can be obtained in vitro, such as appressoria. Identification of genes expressed by infection structures formed following host penetration is more difficult due to contamination with host mRNAs, although recent advances in the isolation of such structures from infected tissue may alleviate this problem $[19,30,50]$.

An alternative approach is to use monoclonal antibodies (MAbs) to identify differentiation-related proteins and carbohydrates. MAbs can be raised against previously uncharacterised molecules that may only be minor components of a complex mixture [16]. Thus, following immunization with whole cells or crude cell extracts, MAbs binding to molecules of interest can be selected using suitable screening assays. This approach has been used to study cell surface components of the zoospores and cysts of Phytophthora and Pythium spp. [15,20], and the intracellular infection structures of Erysiphe pisi [30] and Rhizobium spp. [10].

We have used MAbs to study infection structures formed by the anthracnose fungus, Colletotrichum lindemuthianum, on tissues of Phaseolus vulgaris. In this chapter, we 
describe methods for the isolation of these structures from bean leaves and for the production of cell type-specific MAbs. Our research has focused on (a) the extracellular matrices (ECMs) surrounding conidia, germ-tubes and appressoria, (b) the plasma membrane of appressoria and (c) the biotrophic interface between intracellular hyphae and living host cells. Potential applications of the MAbs in the diagnosis and taxonomy of Colletotrichum are also discussed.

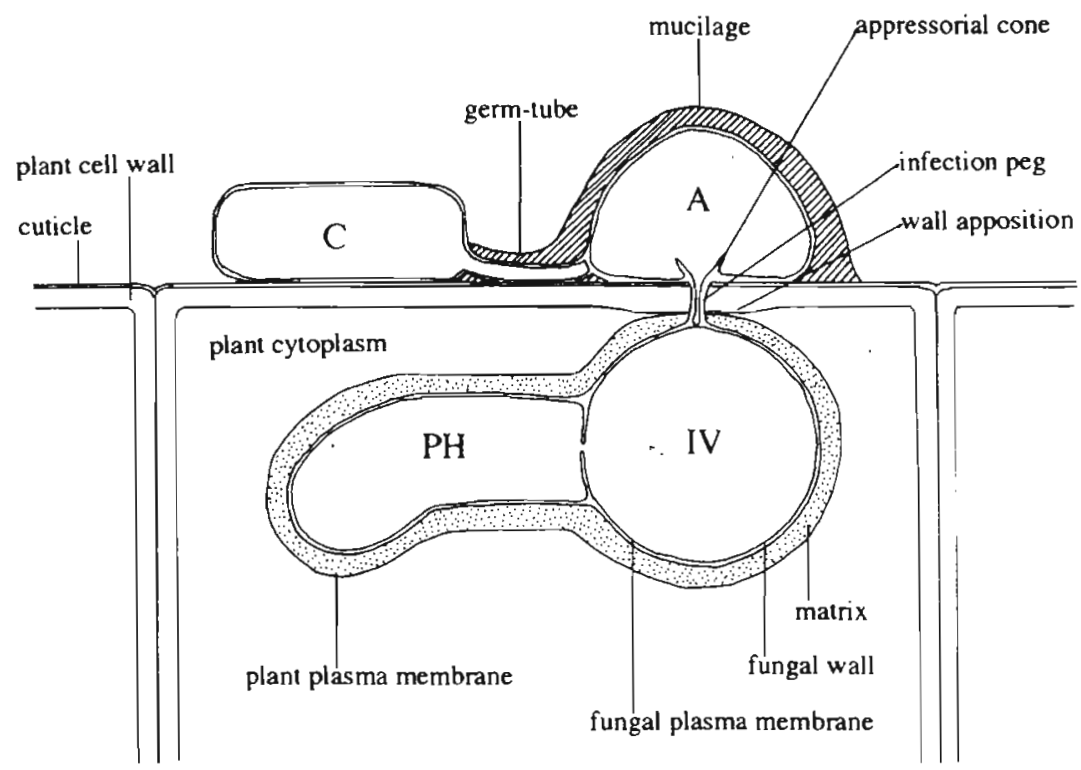

Figure 1. Diagram showing the infection structures produced by $C$. lindemuthianum during infection of a bean epidermal cell. Conidium (C), appressorium (A), infection vesicle (IV) and primary hypha (PH). Reprinted from Pain et al. [50] with permission of the Trustees of The New Phytologist.

\section{Cytology of Infection Process}

The cytology of infection of $P$. vulgaris by $C$. lindemuthianum is well-documented $[5,28,35,40,42,43,48,73]$. The infection structures produced by this pathogen are illustrated diagrammatically in Figure 1.

\subsection{PRE-PENETRATION DEVELOPMENT}

Freeze-substitution studies have shown that the conidia of Colletotrichum species are coated with a layer of short, densely-packed fibres, which are arranged perpendicular to the cell wall (Figure 2) $[37,71]$. In the case of $C$. lindemuthianum, this 'spore coat' 
contains irregularly-shaped pores, and is rich in glycoproteins containing vicinal hydroxyl groups and $N$-acetylgalactosamine residues $[41,47]$. The spore coat may function in the initial rapid attachment of conidia to substrata, which appears to involve hydrophobic proteins on the spore surface $[36,61,77]$.

The conidia of $C$. lindemuthianum germinate in free water to form narrow germtubes, which are enveloped by a fibrillar sheath containing basic proteins and $\alpha$-linked galactose residues [51]. Germ-tubes of several other Colletotrichum species are also surrounded by a fibrillar sheath $[1,18,26,71]$. The germ-tube sheath could perform several important functions, including adhesion to host surfaces, protection from dessication, maintenance of extracellular ion balances and deployment of fungal enzymes $[38,39,59]$. Negative-staining showed that the germ-tube sheath of C. lindemuthianum contains long, loosely-arranged, hair-like structures or 'fimbriae', which protrude from the cell surface (Figure 3) [51]. Fimbriae have been detected in a wide range of other fungi, including C. graminicola $[12,57,75]$, and may be involved in adhesion or contactsensing $[12,58]$.
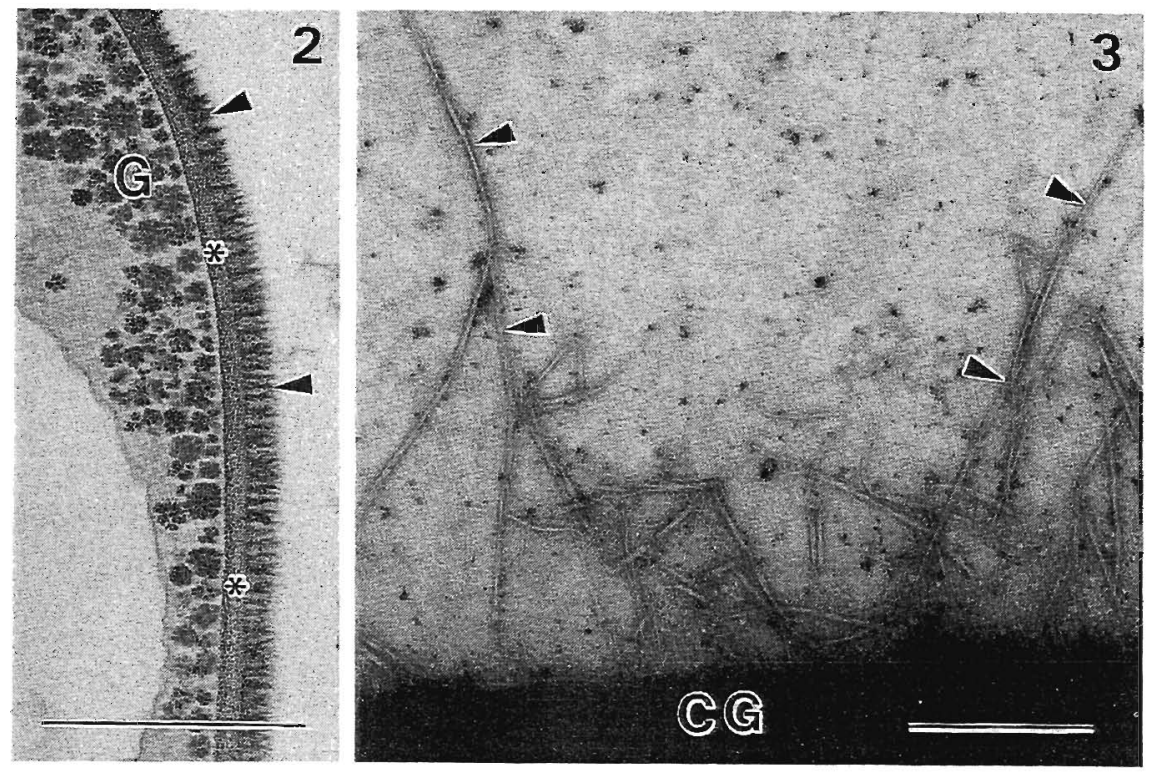

Figure 2. Transverse section through an ungerminated conidium of $C$. lindermuthianum prepared by propane jet-freezing and freeze-substitution and stained for carbohydrates using periodic acid-thiocarbohydrazide-silver proteinate. The spore coat (arrow heads), cell wall (asterisks) and glycogen granules (G) are stained. Bar = $1 \mu \mathrm{m}$. Figure 3. Conidial germ-tube (CG) of $C$. lindemuihianum growing on a Formvar-coated EM grid, stained with sodium phosphotungstate. Long fimbriae (arrowheads) protruding from the cell surface are negatively-stained. Bar $=1 \mu \mathrm{m}$. 
Following contact with the plant cuticle, conidial germ-tubes cease apical growth and their tips swell and differentiate to form appressoria. Maturation of the appressorium involves the deposition of new wall layers containing melanin and the secretion of an ECM. The latter coats the domed region of the cell, forming a thickened ring around its base and extending outwards over the substratum as a thin film $[5,51,70]$. The ECM around $C$. lindemuthianum appressoria contains fimbriae, basic proteins, and residues of mannose, galactose and $N$-acetylglucosamine $[41,51]$. This material is likely to be involved in the firm adhesion of appressoria to the plant surface.

A pore develops in the ventral cell wall and becomes encircled by a funnel-shaped elaboration of the inner appressorial wall, called the appressorial cone [28]. A narrow infection peg or penetration hypha develops as an extension from the cone and penetrates host epidermal cells directly, through the cuticle and cell wall. Penetration of these barriers probably involves fungal enzymes, although appressoria can exert considerable mechanical pressure $[5,32,34]$.

\subsection{INTRACELLULAR BIOTROPHIC PHASE AND THE PLANT-FUNGAL INTERFACE}

Following initial penetration, a large globular infection vesicle expands within the epidermal cell. Large-diameter primary hyphae later develop from the infection vesicle, forming an entirely intracellular mycelium, without true determinate haustoria. In a susceptible bean cultivar, host cells initially survive penetration; they plasmolyse normally, exclude permeability tracers and retain normal ultrastructure [44]. The host plasma membrane expands and invaginates around the developing infection vesicles and primary hyphae through the synthesis and incorporation of a large amount of new membrane material. However, in contrast to the extrahaustorial membranes around haustoria of obligate biotrophs, there is no evidence that the host plasma membrane invaginated around intracellular hyphae of $C$. lindemuthianum becomes structurally or physiologically specialised [40]. Moreover, there is no structure equivalent to a haustorial neckband binding the host plasma membrane to the cell wall of Colletotrichum.

In common with most intracel]ular biotrophs, the infection vesicles and primary hyphae of $C$. lindemuthianum are surrounded by an interfacial matrix layer, which separates the fungal wall from the host plasma membrane $[40,44]$. The liquid or gel-like matrix is rich in carbohydrates and appears to be a product of both plant and fungal activity. Immunogold cytochemistry has indicated the presence of fungal glycoproteins in the matrix [45], while the observation of numerous host Golgi and secretory vesicles around intracellular hyphae suggests that host products are also released into the matrix by exocytosis $[32,40]$. Exocytosis appears to be coupled to membrane re-cycling and possible endocytosis of material from the matrix into the host cell, since clathrin-coated pits are abundant in the invaginated region of the host plasma membrane $[32,40]$. Intracellular hyphae become enmeshed by large numbers of host microtubules that are closely appressed to the invaginated plasma membrane [32]. The interface between 
intracellular hyphae and living host cells is likely to have a key role in recognition phenomena and nutrient transfer [66].

\subsection{NECROTROPHIC PHASE}

About 24 hours after penetration, the host plasma membrane loses functional integrity and infected cells gradually senesce and die [44]. However, biotrophy is re-established in each newly-colonised cell, so that infected cells at the advancing margin of the primary mycelium are alive, while previously infected cells are dead. Approximately 4 days after initial penetration, narrow, thin-walled secondary hyphae develop as branches from the larger primary hyphae. This change in hyphal morphology is associated with an abrupt switch to a destructive, necrotrophic mode of nutrition. Secondary hyphae develop intramurally, as well as intracelluarly, rapidly dissolving host cell walls and killing host protoplasts ahead of infection $[43,44]$. The appearance of secondary hyphae coincides with an increase in the activity of endo-pectin lyase, an enzyme capable of killing and macerating bean tissues [72]. C. lindemuthianum is thus a facultative biotroph or hemibiotroph, initially feeding on living host cells before switching to necrotrophy [43]. C. truncatum and the cowpea anthracnose fungus also have an initial intracellular biotropt ic phase and dimorphic primary and secondary mycelia $[4,49]$. However, in these fur gi biotrophy is confined to a single host epidermal cell.

\section{Production of MAbs}

MAbs were prepared using mice inoculated with two types of immunogen; homogenates of conidia with short germ-tubes grown in liquid culture [52], or homogenates of infection structures isolated from bean leaves [50]. The latter were obtained by homogenizing infected bean leaves, removing plant debris by filtration through a $45 \mu \mathrm{m}$ nylon mesh and collecting the fungal structures by isopycnic centrifugation (IPC) on Percoll, an inert suspension of colloidal silica [62]. The resulting preparation typically contained $2.5-4 \%$ intracellular hyphae (i.e. infection vesicles and primary hyphae), 3\% conidia, 50\% appressoria and $40 \%$ chloroplasts, together with some plant cell wall fragments and starch grains [50]. Approximately $2 \times 10^{5}$ intracellular hyphae can be obtained per gram of leaf tissue, of which over $70 \%$ are alive, as shown by their staining with fluorescein diacetate, normal ultrastructure and ability to grow in nutrient media [50].

A serious problem associated with immunization with complex mixtures of antigens is that the immune response can be dominated by highly antigenic determinants, such as the oligosaccharide side-chains of glycoproteins, which may be common to many molecules [10]. Various techniques have been developed to obtain antibodies to less abundant or less antigenic molecules, including chemical immunosuppression [74], cascade selection [10], neonatal tolerization [20] and co-immunization [6]. In the latter 
technique, polyclonal antisera generated against a mixture of antigens lacking the antigens of interest block the production of unwanted antibodies, possibly through the production of anti-idiotypic antibodies.

We used a co-immunization procedure in an attempt to generate MAbs specific for the intracellular hyphae of $C$. lindemuthianum [53]. First, a polyclonal antiserum was raised against an IPC preparation taken from bean leaves 40 hours after inoculation, which contained conidia, appressoria and plant contaminants but no intracellular hyphae. This antiserum was then incubated with an IPC preparation taken four days after inoculation, when intracellular hyphae were present. The mixture was used to immunise further mice, from which MAbs were prepared by conventional methods. The resulting hybridomas were screened for cell type-specific binding by indirect immunofluoresence (see below), using infection structures isolated from leaves.

From one such experiment we obtained MAbs specific for intracellular hyphae (three), conidia (one), appressoria (one), germ-tubes and appressoria (one) and chloroplasts (ten). Although intracellular hyphae comprised less than $4 \%$ of the immunogen, three out of the $16 \mathrm{MAbs}$ obtained were specific for this cell type, suggesting that co-immunization was effective in increasing the immune response to such hyphae. The relatively small number of hybridomas produced appears to be a feature of the co-immunization procedure [6].

\section{Characterisation of Antigens}

Information on the molecular nature of the antigens recognised by the MAbs can be obtained using Western blotting and antigen modification techniques. The apparent molecular weight of the antigens is determined by separating proteins solubilised from cells or membranes using SDS-polyacrylamide gel electrophoresis, transfer of the proteins to nitrocellulose and Western blotting. However, some proteins are only label]ed when separated under non-reducing conditions. This may indicate that the antibody recognises a conformational epitope.

The antigenic determinant or epitope recognised by an antibody is in the order of four to eight amino acids or sugar residues. Digestion of blotted proteins with a proteolytic enzyme, e.g. pronase or trypsin, will prevent binding of the MAb if a protein epitope is recognised. Similarly, if a MAb no longer binds after treatment of the blotted samples with sodium periodate, which oxidises vicinal hydroxyl groups, the antibody probably recognises a carbohydrate epitope in a glycoprotein antigen. However, carbohydrate epitopes lacking vicinal hydroxyl groups are not sensitive to periodate.

Antigens can be treated in a variety of ways before separation by SDS-PAGE and Western blotting. For example, digestion with peptide- $N$-glycosidase will remove $N$ linked carbohydrate side-chains from glycoproteins [31]. If the MAb recognises a protein epitope, the resulting bands in the Western blot will have a lower molecular weight when compared with untreated samples. Pre-treatment with trifluoromethane sulphonic acid removes both $N$ - and $O$-linked side-chains, decreasing the apparent 
molecular weight of glycoprotein antigens [14]. Phase-partitioning in the detergent Triton X-114 allows the separation of hydrophobic proteins, which partition into the detergent phase, from hydrophilic proteins, which partition into the aqueous phase [56].

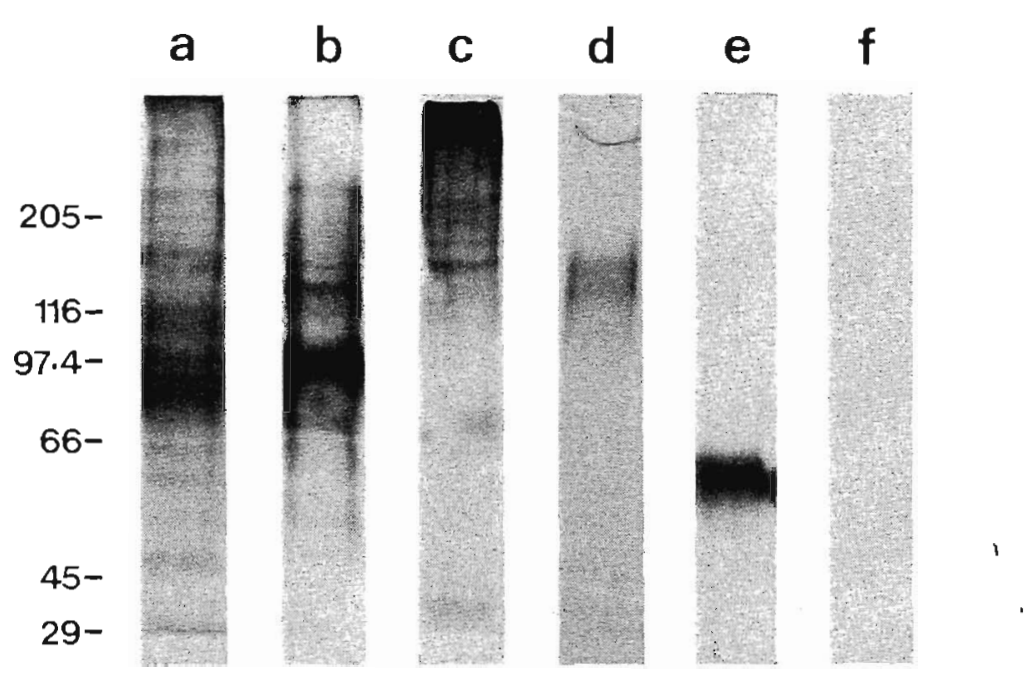

Figure 4. Western blots of proteins extracted from infection structures of $C$. lindemuthianum isolated form bean leaves. Proteins were separated by SDS-PAGE on $7.5 \%$ acrylamide gels under non-reducing conditions, transferred to nitrocellulose and probed with (a) UB20, (b) UB22, (c) UB25, (d) UB26, (e) UB27 and (f) UBIM22 (a control antibody raised to rat bone cells). $M_{r}\left(x_{10}^{-3}\right)$ are given to the left of the blots.

\section{Localisation of Antigens}

For indirect immunofluoresence labelling, infection structures were obtained in vitro by allowing conidia to germinate on multiwell slides or Formvar-coated EM grids, while infection structures isolated from leaves were air-dried onto gelatin-coated microscope slides. The cells were then labelled using conventional procedures, with or without prefixation with $4 \%$ formaldehyde [53].

For EM-immunogold labelling, a post-embedding method was used. The carbohydrate epitopes recognised by MAbs UB20 and UB22 (see below) were wellpreserved by aldehyde fixation, dehydration by the Progressive Lowering of Temperature method [11] and low temperature embedding in LR White resin [52]. However, the protein epitopes recognised by MAbs UB25, UB26 and UB27 (see below) were poorly preserved by this method. Localisation of these antigens was achieved using cryofixation and freeze-substitution [51,53,54]. Cells on polycarbonate or cellophane membranes were cryo-fixed by plunging into liquid propane [21] or by propane jet- 
freezing [17]. For infected tissues, it was necessary to use high-pressure freezing, since this is the only method currently available for cryo-fixation of thick specimens (up to $0.5 \mathrm{~mm}$ ) without the formation of damaging ice crystals [33]. After freeze-substitution in osmium-acetone, samples were embedded at $-20^{\circ} \mathrm{C}$ in LR White resin [53]. Although osmium tetroxide is generally not recommended for immunocytochemistry of protein antigens, its inclusion in the freeze-substitution fluid did not prevent MAb binding.

To allow labelling of both sides of the section, grids were immersed in the immune reagents, while the use of small $(5 \mathrm{~nm})$ colloidal gold particles further increased labelling efficiency [64]. Silver-enhancement was necessary to visualise the gold probe at low magnifications [53].
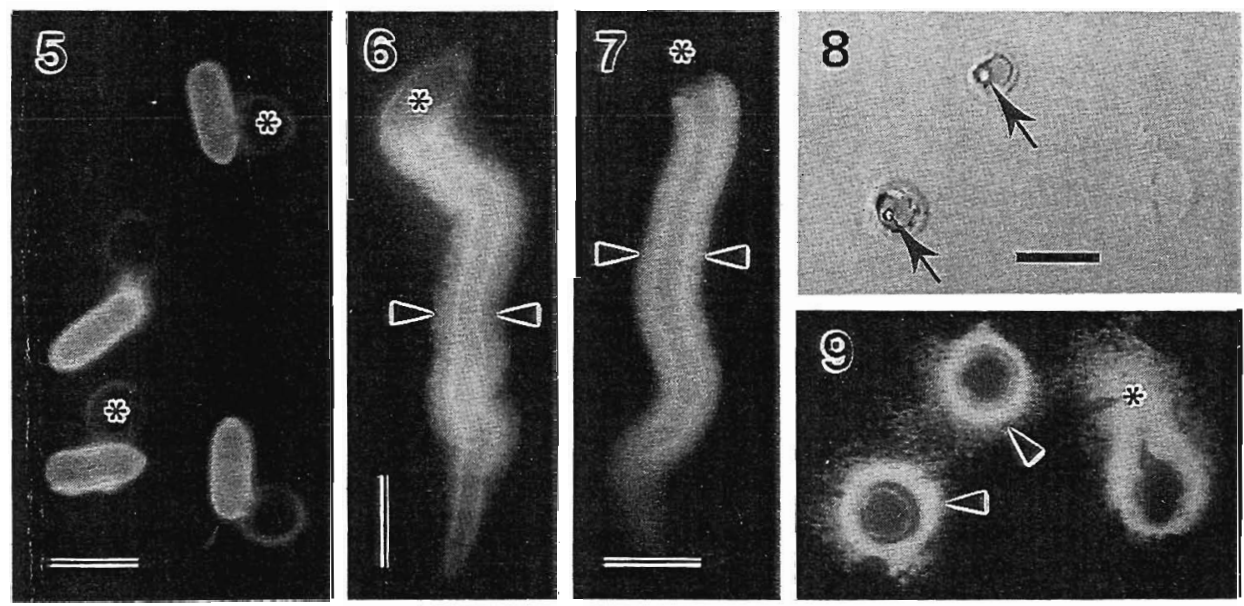

Figures 5-9. Immunofluorescence labelling of germlings of $C$. lindemuthianum grown on glass slides. Bars $=10 \mu \mathrm{m}$. Figure 5. UB20 labels conidia strongly but appressoria (asterisks) are weakly labelled. Figure 6 . UB22 labels the conidium (asterisk) and a fibrillar sheath (arrowheads) around the germ-tube. Figure 7. UB26 labels a fibrillar sheath (arrowheads) around the germ-tube, but not the conidium (asterisk). Figures 8 and 9 . Fragments of appressorial cell walls, containing penetration pores (arrows), remaining attached to a glass slide after ultrasonic disruption, viewed with differential interference contrast $(8)$ or epi-fluorescence (9). UB26 labels haloes (arrowheads) around the disrupted appressoria and a track marking the previous position of a germ-tube (asterisk).

\section{MAbs UB20, UB22 and UB26 Recognise Extracellular Glycoproteins on Conidia, Germ-tubes and Appressoria}

MAbs UB20 and UB22, which had been raised to germlings grown in liquid culture, bound to different carbohydrate epitopes carried on two distinct sets of glycoproteins with a wide range of molecular weights (Figure 4) [52]. Immunofluorescence of germlings grown on glass slides showed that UB20 strongly labelled the spore coat, with only weak labelling of germ-tubes and appressoria (Figure 5). In contrast, UB22 
labelled the fibrillar sheath around germ-tubes strongly, while appressoria and the apices of conidia were labelled less strongly (Figure 6). Fimbriae were not labelled by this antibody [O'Connell, unpublished data]. EM-immunogold labelling of infected bean tissue showed that both MAbs labelled the cell walls of biotrophic intracellular hyphae and the interfacial matrix that surrounds them, supporting earlier conclusions that the interfacial matrix contains fungal glycoproteins [45].

MAb UB26, which had been produced by co-immunization with fungal structures isolated from leaves, recognised a protein epitope on two high molecular weight glycoproteins (133 and $146 \mathrm{kDa}$ ) which contain both $\mathrm{O}$ - and $\mathrm{N}$-linked carbohydrate sidechains (Figure 4) [51]. Immunofluorescence of fungal structures isolated from bean leaves and immunogold labelling of infected tissues showed that UB26 bound to germtubes and appressoria but, unlike UB22, did not bind to conidia or intracellular hyphae [51]. Labelling of germlings grown in vitro showed that UB26 bound to the germ-tube sheath (Figure 7), but the antibody did not label fimbriae in negatively-stained preparations [51].

UB26 also labelled a halo of material surrounding appressoria [51]. When appressoria which had formed on glass were disrupted by sonication, the upper portion of the cell was removed, leaving a small fragment of appressorial wall around the penetration pore attached to the glass (Figure 8) [70]. The halo surrounding these appressorial fragments was still labelled by UB26 (Figure 9), suggesting that the glycoproteins recognised by this antibody adhered firmly to the glass substratum. The glycoproteins also appear to be physically attached to the fungal cell wall, since they were not released into liquid culture media and were not removed by repeated washing during the isolation of germ-tubes and appressoria from infected leaves [51]. These results suggest that the glycoproteins recognised by UB2 6 are involved in the adhesion of germ-tubes and appressoria to substrata.

\section{UB27 Recognises a Glycoprotein Unique to the Plasma Membrane of Appressoria}

MAb UB27 was obtained by co-immunization with fungal structures isolated from bean leaves [54]. Immunofluorescence of such isolated cells showed that the antibody bound only to appressoria and not to any other fungal cell type. This specificity for appressoria was confirmed by immunogold labelling of freeze-substituted fungal germlings, grown either on plastic membranes or on plant surfaces (Figures 10 and 11). Within appressoria, the antigen was concentrated along the plasma membrane-wall interface, although the cell wall and ECM were also weakly labelled. Labelling was absent from the basal penetration pore and a region surrounding the pore, including the appressorial cone (Figure 10). An identical labelling pattern was observed with immunofluorescence, using appressoria mechanically removed from leaves or disrupted by ultrasonic vibration or freeze-fracture. In such appressoria, the internal surface of the cell wall was intensely labelled, except for a circular region around the penetration 

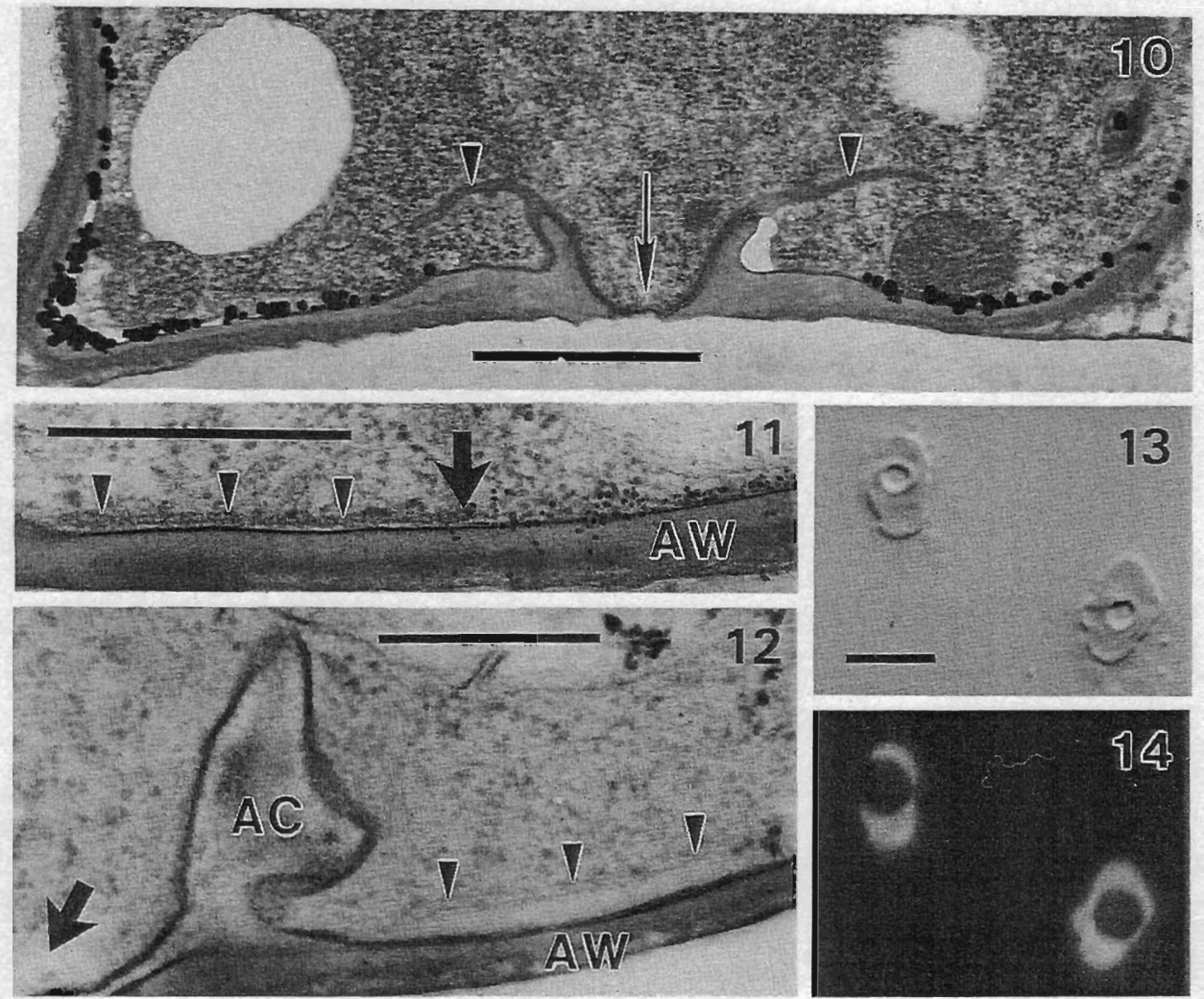

Figure 10. Section through the base of an appressorium of $C$. lindemuthianum formed on a polycarbonate membrane, cryo-fixed by plunge-freezing in liquid propane and immunogold labelled with UB27 $(5 \mathrm{~nm}$ colloidal gold with silver enhancement). The plasma membrane is labelled, except in the region of the penetration pore (arrow) and appressorial cone (arrowheads). Bar $=1 \mu \mathrm{m}$. Figure 11. Section through the base of an appressorium formed on a bean hypocotyl, cryo-fixed by high-pressure freezing and immunogold labelled with UB27. Labelling of the plasma membrane and appressorial wall (AW) stops at the point indicated by the arrow. A flattened cisterna of smooth membrane (arrowheads) is associated with the unlabelled region of the plasma membrane. Bar $=0.5 \mu \mathrm{m}$. Figure 12. Section through the base of an appressorium formed on a bean hypocotyl (chemical fixation and dehydration), stained with PACP. The plasma membrane lining the appressorial wall (AW), appressorial cone (AC) and penetration pore (arrow) is uniformly stained. A cisterna of smooth membrane (arrowheads) encircling the pore is not stained. Bar $=0.5$ $\mu \mathrm{m}$. Figures 13 and 14. Fragments of appressorial cell walls, containing penetration pores, remaining attached to a glass slide after freeze-fracture (crushing under liquid nitrogen), labelled with UB27 and viewed with differential interference contrast (13) or epi-fluorescence (14). The internal surface of the wall is labelled, except for a circular region around the pore. $B a r=10 \mu \mathrm{m}$. Figures 10 and 11 reprinted from Pain et al. [54] with the permission of Springer-Verlag.

pore (Figures 13 and 14). Intact appressoria, on the other hand, were poorly labelled by UB27 in immunofluorescence experiments, presumably because the antibodies could not penetrate the melanised cell wall. 
In Westem blots of appressorial proteins (Figure 4), UB27 recognised a protein epitope in a single glycoprotein $(\mathrm{Mr} 48-50 \mathrm{kDa}$ ) with large, $O$-linked carbohydrate sidechains. In phase-separation experiments, the glycoprotein partitioned into the detergent phase, indicating that it is a hydrophobic protein and possibly an integral membrane component [54].

The region of appressorial plasma membrane not labelled by UB27 was sometimes closely associated with a flattened cisterna of smooth membrane, which appeared to form a ring around the penetration pore (Figure 11). This membrane ring, which was also visible in chemically-fixed appressoria, was not stained by periodic acid-chromic acidphosphotungstic acid (PACP, Figure 12), suggesting that it is not derived from the plasma membrane. We therefore speculate that this structure is a component of the fungal endomembrane system.

Our data provide the first evidence that the plasma membrane of Colletotrichum appressoria is differentiated into two distinct domains; one containing the glycoprotein recognised by UB27 and another, around the penetration pore, from which it is absent. Physical links between this glycoprotein and components of the cell wall and/or cytoskeleton may be involved in maintaining separation between the two membrane domains [54]. Using PACP staining, Smereka et al. [65] found that the plasma membrane of Venturia inaequalis appressoria is also specialised around the penetration pore. However, the plasma membrane of $C$. lindemuthianum appressoria was uniformly stained by PACP (Figure 12). Since the appressorial plasma membrane is continuous with that of the infection peg and infection vesicle, specialization of the plasma membrane in the pore region might be a necessary preparation for subsequent penetration and intracellular biotrophic development within host cells.

The distribution of the glycoprotein recognised by UB27 within appressoria suggests that it may play a role in establishing cell polarity, perhaps by determining the position of the penetration pore. Altematively, it could be involved in the synthesisis or assembly of wall polymers specific to the appressorium.

\section{UB25 Recognises Glycoproteins Restricted to the Surface of Biotrophic Intracellular Hyphae}

MAb UB25, which had been obtained by co-immunization with infection structures isolated from bean leaves [53], bound specifically to infection vesicles and primary hyphae in immunofluorescence experiments (Figures 15 and 16). In Westem blots, this antibody recognised a protein epitope carried on a set of $\mathrm{N}$-linked glycoproteins (Figure 4).

Immunogold labelling of bean tissues prepared by high-pressure freezing and freezesubstitution showed that these glycoproteins were present in the cell walls of intracellular infection vesicles and primary hyphae and in the interfacial matrix layer that surrounds them (Figure 17). In contrast, the glycoproteins were not detected around primary hyphae growing in intercellular spaces. They were also absent from hyphae 

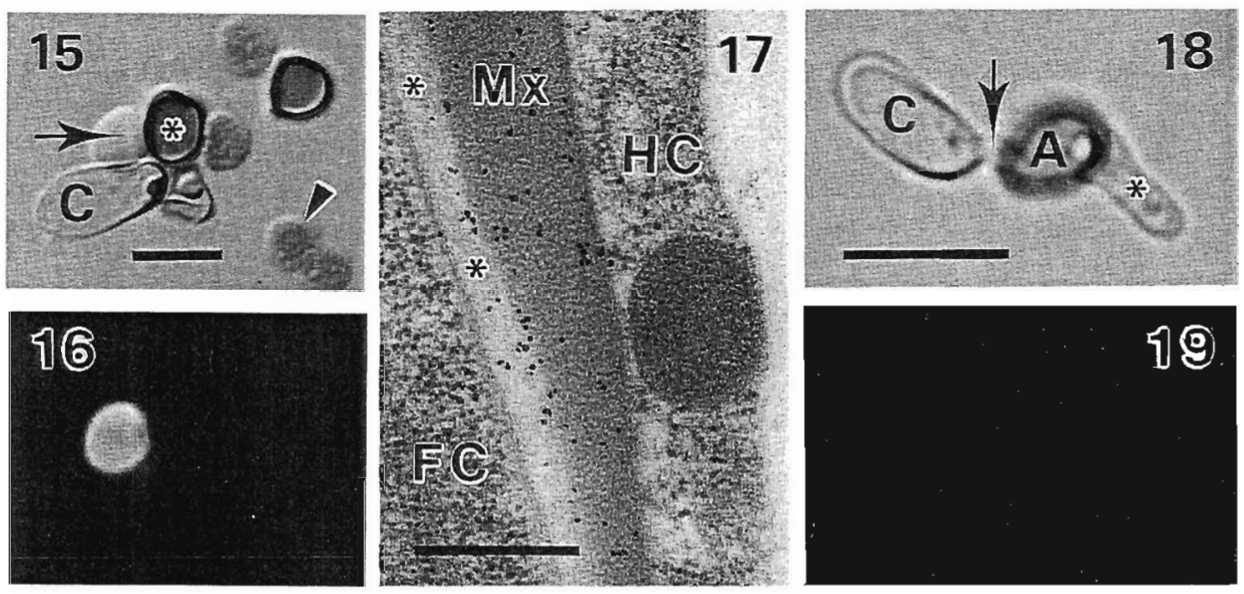

Figures 15 and 16. Immunofluorescence labelling with UB25 of infection structures of $C$. lindemuthianum isolated from bean leaves, viewed with differential interference contrast (15) or epi-fluorescence (16). Infection vesicle (arrow) is labelled but appressoria (asterisk), conidium (C) and chloroplasts (arrowhead) are not. Bar $=10 \mu \mathrm{m}$. Figure 17. Part of a primary hypha in a bean epidermal cell, cryo-fixed by high-pressure freezing and immunogold labelled with UB25 ( $5 \mathrm{~nm}$ colloidal gold with silver enhancement). The fungal wall (asterisks) and interfacial matrix $(\mathrm{Mx})$ are labelled, but the host cytoplasm $(\mathrm{HC})$ and fungal cytoplasm $(\mathrm{FC})$ are not. Bar $=0.5 \mu \mathrm{m}$. Figures 18 and 19 . Immunofluorescence labelling with UB25 of germling penetrating a Formvar plastic membrane (100 nm thick), viewed with bright field (18) or epi-fluoresence (19). The conidium (C), conidial germ-tube (arrow) and appressorium (A) above the membrane and the appressorial germ-tube (asterisk) below the membrane are not labelled. Bar $=10 \mu \mathrm{m}$. Figures 17-19 are reprinted from Pain et al. [53] with permission of the Trustees of The New Phytologist.

growing on the plant surface and from appressorial germ tubes (Figures 18 and 19), which are formed in vitro after penetration of plastic membranes and are developmentally equivalent to infection vesicles. The glycoproteins recognised by UB25 are thus entirely confined to the biotrophic interface between intracellular hyphae and living host protoplasts.

While the glycoproteins identified by UB25 are only expressed on the surface of intracellular hyphae, the expression of other glycoproteins, e.g. those recognised by MAb UB26 and the lectin GSI-B4, appears to be suppressed (see above) [51]. Thus, the fungal cell wall becomes specialised during growth within living host cells, in contrast to the host plasma membrane, which appears to remain largely unmodified [40]. Such changes in the composition of the fungal cell surface presented to the host plasma membrane may be important in the establishment of a compatible interaction and maintenance of host cell viability. This view is supported by the finding that glycoproteins recognised by UB25 are present very soon after initial penetration of epidermal cells, when the fungus first contacts the host plasma membrane. 


\section{Use of MAbs for Selective Cell Enrichment}

Although intracellular hyphae were purified 3000-fold from leaf homogenates after IPC on Percoll, such preparations still contained only $2.5-4 \%$ hyphae, due to major contamination with other fungal cell types and plant components (see above). The specificity of MAb UB25 for these hyphae was exploited to purify them further using immunomagnetic separation. IPC preparations were first incubated with UB25, washed by centrifugation and then incubated with magnetic beads coated with goat anti-mouse IgG antibodies. Magnetic separation enriched the intracellular hyphae 10-fold, yielding a sample which contained $30-40 \%$ hyphae, of which $60 \%$ were viable [50]. More recently, it has been possible to obtain preparations containing up to $95 \%$ intracellular hyphae with yields of $1-3 \times 10^{5}$ per gram of leaf tissue. This was achieved by washing hyphae attached to the magnetic beads with buffer and repeating the magnetic separation step (N.A. Pain, unpublished results). Immunomagnetic separation has been widely used in animal cell biology and microbiology for the purification of cells, bacteria and viruses from mixed populations [62], but this is the first report of its use for the purification of fungal cells. The purified intracellular hyphae are now being used for further immunizations to generate specific antibodies.

\section{Interspecific Cross-reactions of MAbs and their Relevance to the Taxonomy and Diagnosis of Colletotrichum}

Until recently, the taxonomy of the genus Colletotrichum was very confused and in some cases inaccurate, being based largely upon host origin and descriptive criteria such as conidial size and morphology. Many isolates with indistinguishable morphologies were given different names simply because they were obtained from different host plants. As a result, more than 1000 different species were recognised by von Arx in 1957 [3]. When host origin was given less emphasis, the number of species was reduced to less than 40 [68].

C. lindemuthianum was initially viewed as a host-specific form of $C$. gloeosporioides [3] but was later regarded as a distinct species $[67,68]$. In a recent molecular analysis, based on sequences of rDNA, Sherriff et al. [63] compared isolates of $C$. lindemuthianum from bean ( $P$. vulgaris) and cowpea (Vigna unguiculata) with other species of Colletotrichum. The results revealed several important findings (Figure 20). First, C. lindemuthianum from bean is clearly not a form of $C$. gloeosporioides. Second, the cowpea anthracnose fungus is neither a form of $C$. lindemuthianum nor of $C$. gloeosporioides; its present taxonomic status remains unclear [4]. Finally, these data clearly show that $C$. lindemuthianum is closely related to three other species, namely $C$. orbiculare $(=C$. lagenarium), $C$. malvarum and $C$. trifolii, which are distinct from all other members of the genus. It was thus proposed that $C$. lindemuthianum is a 
Phaseolus-specific form of a species complex which should be correctly regarded as $C$. orbiculare (Berk. et Mont) [63].

Associated morphological and cytochemical studies on conidia revealed new criteria that were valuable in identifying $C$. lindemuthianum and other forms of $C$. orbiculare [46]. When produced, the conidia of all Colletotrichum species are aseptate, and in species of the $C$. orbiculare complex they remain aseptate after germination. However, in all other species a septum is produced in conidia during germination. Conidia of the C. orbiculare complex also differ from those of all other species in being coated with glycoproteins that are recognised by the lectin BPA $[41,46]$.

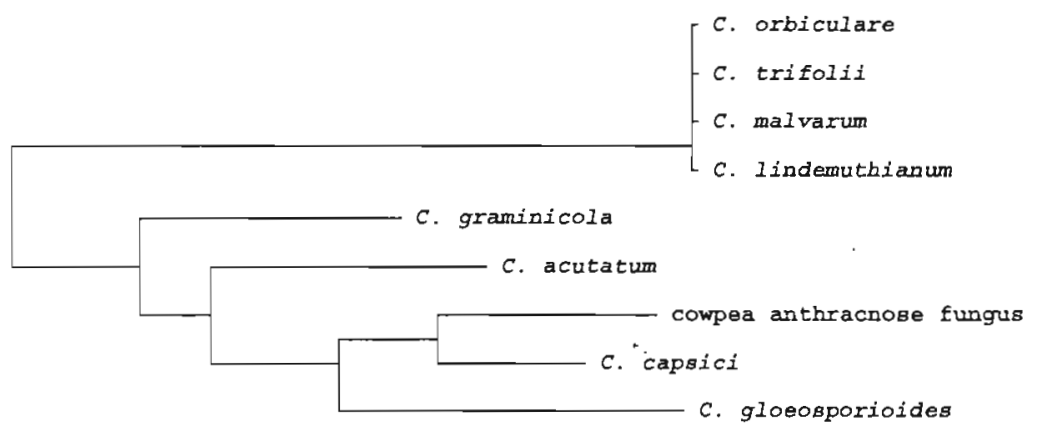

Figure 20. Dendrogram, based on analysis of TTS2 and D2 rDNA sequences, illustrating the relatedness of the $C$. orbiculare complex (C. orbiculare, $C$. trifolii, $C$. malvarum and $C$. lindemuthianum) and their distinction from other members of the genus. Scale: $2 \mathrm{~mm}$ horizontal distance is equivalent to $0.1 \%$ difference in nucleotides. Data taken from Sherriff et al. [63].

The patterns of cross-reaction shown by MAbs raised to cells of $C$. lindemuthianum correlate well with these molecular and morphological data and fully support the distinction made between the $C$. orbiculare complex and other species. For example, when the MAbs UB20 and UB22 were screened by ELISA for cross-reaction with 12 Colletotrichum species, UB20 bound only to members of the $C$. orbiculare complex, while UB22 also cross-reacted weakly with $C$. acutatum, $C$. graminicola and $C$. gloeosporioides. Neither MAb cross-reacted with the cowpea anthracnose fungus [52]. Similarly, MAb UB26 cross-reacted with the germ-tubes and appressoria of all members of the C. orbiculare complex in immunofluorescence experiments but did not bind to those of six other species, which included the cowpea anthracnose fungus [51].

Some of the MAbs may be valuable for disease diagnosis and epidemiological studies. For example, UB20 and UB26 could be used to distinguish between the $C$. orbiculare complex and morphologically similar species, such as C. gloeosporioides, that affect the same crop [52]. Preliminary results indicate that UB20 can be used in rapid spore agglutination and dot-blot tests [O'Connell, unpublished data]. These and other applications of MAbs in the diagnosis of fungal diseases have been reviewed recently by Dewey and Oliver [13]. 
TABLE 1. Binding characteristics of MAbs for cell surfaces of $C$. lindemuthianum conidia and infection structures, and nature of the antigens recognised

\begin{tabular}{|c|c|c|c|c|c|c|}
\hline MAb & $\begin{array}{l}\text { Molecular nature of } \\
\text { glycoproteins } \\
\text { recognised }(\mathrm{kDa})\end{array}$ & $\begin{array}{l}\text { Epitope } \\
\text { recognised }\end{array}$ & Conidia & Germ-tubes & Appressoria & $\begin{array}{l}\text { Intracellular } \\
\text { Hyphae }\end{array}$ \\
\hline UB20 & $(29-205)$ & $\mathrm{CHO}$ & ++ & + & + & + \\
\hline UB22 & $(50-205)$ & $\mathrm{CHO}$ & + & tr & + & + \\
\hline UB26 & $\begin{array}{l}(133,146) \\
N \text { - and } O \text {-linked }\end{array}$ & Protein & - & ++ & ++ & - \\
\hline UB27 & $(48)$ & $\mathrm{CHO}$ & - & - & ++ & - \\
\hline UB25 & $\begin{array}{l}\text { (multimers of } 44 \text { ) } \\
\mathrm{N} \text {-linked }\end{array}$ & Protein & - & - & - & +t \\
\hline
\end{tabular}

CHO carbohydrate, ++ strong, + weak, - unlabelled. Data from Pain et al. [51-54].

\section{Conclusions and Future Prospects}

We have used MAbs to identify and partially characterise a number of developmentallyregulated glycoproteins present in $C$. lindemuthianum infection structures, which may be relevant to adhesion, morphogenesis, recognition and biotrophy. The properties of the MAbs and the glycoproteins that they bind to are summarised in Table 1.

The antibodies could be used in several ways to provide further information on the nature of these glycoproteins and their role in the infection process. For example, MAbs could be included in functional assays to study their possible inhibitory effect on adhesion, penetration or intracellular development. They could also be used for immunoaffinity chromatography to purify the glycoproteins for carbohydrate analysis and amino acid sequencing [2]. Sequence information could be used to generate oligonucleotide probes for screening a genomic or cDNA library [60]. Alternatively, polyclonal antibodies raised to the purified proteins could be used to immunoscreen cDNA expression libraries [60]. MAbs which recognise protein epitopes, such as UB25, UB26 and UB27, could be used to screen expression libraries directly. Gene disruption or replacement [9] or antisense techniques [25] would provide proof of the function of genes cloned in these ways. Compared to differential or subtractive hybridization, MAbs offer a more targeted, albeit slower, approach to the identification of genes involved in the development and function of fungal infection structures and biotrophic interfaces. 


\section{Acknowledgements}

This work was supported by a BBSRC LINK award (Grant No. P01439). IACR-Long Ashton receives grant-aided support from the Biotechnology and Biological Sciences Research Council of the United Kingdom. We would like to thank Philip Keen and Caroline Nash for providing Figures 5 and 20, respectively, and Ellen Cooke for assistance with the preparation of the manuscript.

\section{References}

1. Akai, S. and Ishida, N. (1968) An electron microscopic observation on the germination of conidia of Colletorrichum lagenarium, Mycopath. et Mycol. Appl. 34, 337-345.

2. Arvieux, J. and Williams, A.F. (1988) Immunoaffinity chromatography, in D. Catty (ed.), Antibodies, Vol. I, A Practical Approach, IRL Press, pp.113-136.

3. Arx, J.A. von (1957) Die Arten der Gattung Colletotrichum Cda, Phytopath. Z. 29, 413-468.

4. Bailey, J.A., Nash, C., O'Connell, R.J., and Skipp, R.A. (1990) Infection process, host specificity and taxonomic relationships of a Colletotrichum species causing anthracnose disease of cowpea, Vigna unguiculata, Mycol. Res. 94, 810-814.

5. Bailey, J.A., O'Connell, R.J., Pring, R.J., and Nash, C. (1992) infection strategies of Colletorrichum species, in J.A. Bailey and M.J. Jeger (eds.), Colletotrichum. Biology, Pathology and Control, CAB International, Wallingford, pp. 88-120.

6. Barclay, S.L. and Smith, A.M. (1986) Rapid isolation of monoclonal antibodies specific for cell surface differentiation antigens, Proc. Nat. Acad. Sci. USA 83, 4336-4340.

7. Bhairi, S., Buckley, E.H., and Staples, R.C. (1990) Protein synthesis and gene expression during appressorium formation in Glomerella magna, Exp. Mycol. 14, 207-217.

8. Bhairi, S.M., Staples, R.C., Freve, P., and Yoder, O.C. (1989) Characterization of an infection structurespecific gene from the rust fungus Uromyces appendiculatus, Gene 81, 237-243.

9. Bowen, J.K., Templeton, M.D., Sharrock, K.R., Crowhurst, R.N., and Rikkerink, E.H.A. (1995) Gene inactivation in the plant pathogen Glomerella cingulata: three strategies for the disruption of the pectin lyase gene $p n L A$, Mol. Gen. Genet. 246, 196-205.

10. Bradley, D.J., Wood, E.A., Larkins, A.P., Galfre, G., Butcher, G.W., and Brewin, N.J. (1988) Isolation of monoclonal antibodies reacting with peribacteroid membranes and other components of pea root nodules containing Rhizobium leguminosarum, Planta 173, 149-160.

11. Carlemalm, E., Villiger, W., Hobot, J.A., Acetarin, J-D., and Kellenberger, E. (1985) Low temperature embedding with Lowicryl resins: two new formulations and some applications, J. Microsc. 140, 55-63.

12. Day, A.W. and Gardiner, R.B. (1987) Fungal fimbriae, Studies in Mycology 30, 333-349.

13. Dewey, F.M. and Oliver, R. (eds.) (1994) Modern Assays for Plant Pathogenic Fungi: Identification, Delection and Quantification, CAB Intemational.

14. Edge, A.S.B., Faltynek, C.R., Hof, L., Reichert, L.E., and Weber, P. (1981) Deglycosylation of glycoproteins by trifluoromethane sulfonic acid, Anal. Biochem. 118, 131-137.

15. Estrada-Garcia, M.T., Green, J.R., Booth, J.M., White, J.G., and Caliow, J.A. (1989) Monoclonal antibodies to cell surface components of zoospores and cysts of the fungus Pythium aphanidermatum reveal species-specific antigens, Exp. Mycol. 13, 348-355.

16. Galfre, G. and Milstein, C. (1981) Preparation of monoclonal antibodies: strategies and procedures, Melhods in Enzymology 73, 3-46.

17. Gilkey, J.C. and Staehelin, L.A. (1986) Advances in ultrarapid freezing for the preservation of cellular ultrastructure, $J$. Electron Microsc. Techn. 3, 177-210. 
18. Griffiths, D.A. and Campbell, W.P. (1973) Fine structure of conidial germination and appressorial development in Colletotrichum atramentarium, Trans. Br. Mycol. Soc. 61, 529-536.

19. Hahn, M. and Mendgen, M. (1992) Isolation by Con A binding of haustoria from different rust fungi and comparison of their surface qualities, Proloplasma 170, 95-103.

20. Hardham, A.R., Gubler, F., Dunjec, J., and Elliott, J. (1991) A review of methods for the production and use of monoclonal antibodies to study zoosporic plant pathogens, J. Microsc. 162, 305-318.

21. Hoch, H.C. (1986) Freeze-substitution in fungi, in H.C. Aldrich and W.J. Todd (eds.), Electron Microscopy of Microorganisms, Plenum, New York, pp.183-212.

22. Hoch, H.C. and Staples, R.C. (1991) Signaling for infection structure formation in fungi, in G.T. Cole and H.C. Hoch (eds.), The Fungal Spore and Disease Initiation in Plants and Animals, Plenum Press, New York, pp. 25-46

23. Hwang, C.-S. and Kolattukudy, P.E. (1995) Isolation and characterization of genes expressed uniquely during appressorium formation by Colletotrichum gloeosporioides conidia induced by the host surface wax, Mol. Gen. Genet. 247, 282-294.

24. Hwang, C.-S., Flaishman, M.E., and Kolattukudy, P.E. (1995) Cloning of a gene expressed during appressorium formation by Colletotrichum gloeosporioides and a marked decrease in virulence by disruption of this gene, Plant Cell 7, 183-193.

25. Judelson, H.S., Dudler, R., Pieterse, C.M.J., Unkles, S.E., and Michelmore, R.W. (1993) Expression and antisense inhibition of transgenes in Phytophthora infestans is modulated by choice of promoter and position effects, Gene 133, 63-69.

26. Kozar, F., and Netolizky, H.J. (1978) Studies on hyphal development and appressorium formation of Colletotrichum graminicola, Can. J. Bot. 56, 2234-2242.

27. Kubo, Y., Nakamura, H., Kobayashi, K., Okuno, T., and Furusawa, I. (1991) Cloning of a melanin biosynthetic gene essential for appressorial penetration of Colletọtrichum lagenarium, Mol. PlantMicrobe Interact. 4, 440-445.

28. Landes, M. and Hoffman, G.M. (1979) Zum Keimungs- und Infektionsverlauf bei Colletotrichum lindemuthianum auf Phaseolus vulgaris, Phytopath. Z. 95, 259-273.

29. Lee, Y-H. and Dean, R.A. (1993) Stage-specific gene expression during appressorium formation of Magnaporthe grisea, Exp. Mycol. 17, 215-222.

30. Mackie, A.J., Roberts, A.M., Callow, J.A., and Green, J.R. (1991) Molecular differentiation in pea powdery mildew haustoria -idenfication of a $62 \mathrm{kDa} N$-linked glycoprotein unique to the haustorial plasma membrane, Planta 183, 399-408.

31. Maley, F., Trimble, R.B., Tarentino, A.L., and Plummer, T.H. (1989) Characterization of glycoproteins and their associated oligosaccharides through the use of endoglycosidases, Anal. Biochem. 180, 195-204

32. Mendgen, K. and Deising, H. (1993) Infection structures of fungal plant pathogens - a cytological and physiological evaluation, New Phytol. 124, 193-213.

33. Mendgen, K., Welter, K., Scheffold, F., and Knauf-Beiter, G. (1991) High pressure freezing of rust infected plant leaves, in K. Mendgen and D.E. Lesemann (eds.), Electron Microscopy of Plant Pathogens, Heidelberg, Springer-Verlag, pp. 31-42.

34. Mercer, P.C., Wood, R.K.S, and Greenwood, A.D. (1971) Initial infection of Phaseolus vulgaris by Colletotrichum lindemuthianum, in T.F. Preece and C.H. Dickinson (eds.), Ecology of Leaf Surface Microorganisms, Academic Press, London, pp. 381-390.

35. Mercer, P.C., Wood, R.K.S., and Greenwood, A.D. (1975) Ultrastructure of the parasitism of Phaseolus vulgaris by Colletotrichum lindemuthianum, Physiol. Plant Pathol. 5, 203-214.

36. Mercure, E.W., Leite, B., and Nicholson, R.L. (1994) Adhesion of ungerminated conidia of Colletotrichum graminicola to artificial hydrophobic surfaces, Physiol. Mol. Plant Pathol. 45, 421-440.

37. Mims, C.W., Richardson, E.A., Clay, R.P., and Nicholson, R.L. (1995) Ultrastructure of conidia and the conidium aging process in the plant pathogenic fungus Colletotrichum graminicola, Int. J. Plant Sci. 156, 9-18.

38. Moloshok, T.D., Leinhos, G.M.E., Staples, R.C., and Hoch, H.C. (1993) The autogenic extracellular environment of Uromyces appendiculatus urediospore germlings, Mycologia 85, 392-400 
39. Nicholson, RL. and Epstein, L. (1991) Adhesion of fungi to the plant surface. Prerequisite for pathogenesis, in G.T. Cole and H.C. Hoch (eds.), The Fungal Spore and Disease Initiation in Plants and Animals, Plenum, New York pp 3-23.

40. O'Connell, R.J. (1987) Absence of a specialized interface between intracellular hyphae of Colletotrichum lindemuthianum and cells of Phaseolus vulgaris, New Phytol. 107, 725-734.

41. O'Connell, R.J. (1991) Cytochemical analysis of infection structures of Colletotrichum lindemuthianum using fluorochrome-labelled lectins, Physiol. Mol. Plant Pathol. 39, 189-200.

42. O'Connell, R.J. and Bailey, J.A. (1986) Cellular interactions between Phaseolus vulgaris and the hemibiotrophic fungus Colletotrichum lindemuthianum, in J.A. Bailey (ed.), Biology and Molecular Biology of Plant-Pathogen Interactions, NATO ASI Series H, Vol.1, Springer-Verlag, Berlin, pp. 39-49.

43. O'Connell, R.J. and Bailey, J.A. (1991) Hemibiotrophy in Colletotrichum lindemuthianum, in K. Mendgen and D.-E. Lesemann (eds.), Electron Microscopy of Plant Pathogens, Springer-Verlag, Berlin, pp. 211-222.

44. O'Connell, R.J., Bailey, J.A., and Richmond, D.V. (1985) Cytology and physiology of infection of Phaseolus vulgaris infected by Colletotrichum lindemuthianum, Physiol. Plant Pathol. 27, 75-98.

45. O'Connell, R.J., Bailey, J.A., Vose, I.R., and Lamb, C.J. (1986) Immunogold labelling of fungal antigens in cells of Phaseolus vulgaris infected by Colletotrichum lindemuthianum, Physiol. Mol. Plant Pathol. 28, 99-105.

46. O'Connell, R.J., Nash, C., and Bailey, J.A. (1992) Lectin cytochemistry: a new approach to understanding cell differentiation, pathogenesis and taxonomy in Colletotrichum, in J.A.Bailey and M.J. Jeger (eds.), Colletotrichum. Biology, Pathology and Control, CAB International, Wallingford, pp 67-87.

47. O'Connell, R.J., Pain, N.A., Hutchison, K.A., Jones, G.L., and Green, J.R. (1996) Ultrastructure and composition of the cell surfaces of infection structures formed by the fungal plant pathogen Colletotrichum lindemuthianum, J. Microsc. (in press).

48. O'Connell, R.J. and Ride, J.P. (1990) Chemical detection and ultrastructural localization of chitin in cell walls of Colletotrichum lindemuthianum, Physiol. Mol. Plant Pathol. 37, 39-53

49. O'Connell, R.J., Uronu, A.B., Waksman, G., Nash, C., Keon, J.P.R., and Bailey, J.A. (1993) Hemibiotrophic infection of Pisum sativum by Colletotrichum truncatum, Plant Pathol. 42, 774-783

50. Pain, N.A., Green, J.R., Gammie, F., and O'Connell, R.J. (1994) Immunomagnetic isolation of viable intracellular hyphae of Colletotrichum lindemuthianum (Sacc. \& Magn.) Briosi \& Cav. from infected bean leaves using a monoclonal antibody. New Phytol. 127, 223-232.

51. Pain, N.A., Green, J.R., Jones, G.L., and O'Connell, R.J. (1996) Composition and organisation of extracellular matrices around germ-tubes and appressoria of Colletotrichum lindemuthianum, Protoplasma (in press).

52. Pain, N.A., O'ConnelI, R.J., Bailey, J.A., and Green, J.R. (1992) Monoclonal antibodies which show restricted binding to four Colletotrichum species: $C$. lindemuthianum, $C$. malvarum, $C$. orbiculare and C. trifolii, Physiol. Mol. Plant Pathol. 41, 111-126.

53. Pain, N.A., O'Connell, R.J., Mendgen, K., and Green, J.R. (1994) Identification of glycoproteins specific to biotrophic intracellular hyphae formed in the Colletotrichum lindemuthianum-bean interaction, New Phytol. 127, 233-242.

54. Pain, N.A., O'Connell, R.J., and Green, J.R. (1995) A plasma membrane-associated protein is a marker for differentiation and polarisation of Colletotrichum lindemuthianum appressoria, Protoplasma (in press)

55. Perpetua, N.S., Kubo, Y., Okuno, T., and Furusawa, I. (1994) Restoration of pathogenicity of a penetration-deficient mutant of Colletotrichum lagenarium by DNA complementation, Curr. Genet. 25, 41-46.

56. Pryde, J.G. (1986) Triton X-114: a detergent that has come in from the cold, Trends in Biochem. Sci. 11, 160-163.

57. Rghei, N.A., Castle, A.J., and Manocha, M.S. (1992) Involvement of fimbriae in fungal hostmycoparasite interaction, Physiol. Mol. Plant Pathol. 41, 139-148. 
58. Romantschuk, M. (1992) Attachment of plant pathogenic bacteria to plant surfaces, Ann. Rev. Phytopathol. 30, 225-243.

59. Ruel, K. and Joseleau, J-P. (1991) Involvement of an extracellular glucan sheath during degradation of Populus wood by Phanerochaete chrysosporium, Appl. Environ. Microbiol. 57, 374-384.

60. Sambrook, J., Fritsch, E.F., and Maniatis, T. (1989) Molecular Cloning: a Laboratory Manual, Cold Spring Harbor Laboratory Press.

61. Sela-Buurlage, M.B., Epstein, L., and Rodriguez, R.J. (1991) Adhesion of ungerminated Colletotrichum musae conidia, Physiol. Mol. Plant Pathol. 39, 345-352.

62. Sharpe, P.T. (1988) Methods of Cell Separation: Laboratory Techniques in Biochemistry and Molecular Biology, Vol. 18, R.H. Burdon and P.H. van Knippenberg (Series eds.), Elsevier, Amsterdam.

63. Sherriff, C., Whelan, M.J., Amold, G.M., Lafay, J-F., Brygoo, Y., and Bailey, J.A. (1994) Ribosomal DNA sequence analysis reveals new species groupings in the genus Colletotrichum, Exp. Mycol. 18, 121-138.

64. Slot, J.W. and Geuze, H.J. (1981) Sizing of Protein A - colloidal gold probes for immunoelectron microscopy, J. Cell Biol. 90, 533-536.

65. Smereka, K.J., Machardy, W.E, and Kausch, A.P. (1987) Cellular differentiation in Venturia inaequalis ascospores during germination and penetration of appie leaves, Can. J. Bot. 65, 2549-2561.

66. Smith, S.E. and Smith, F.A. (1990) Structure and function of the interfaces in biotrophic symbioses as they relate to nutrient transport, New Phytol. 114, I-38.

67. Sutton, B.C. (1980) The Coelomycetes, Commonwealth Mycological lnstitute, Kew, London.

68. Sutton, B.C. (1992) The genus Glomerella and its anamorph Colletotrichum, in J.A. Bailey and M.J. Jeger (eds.), Colletotrichum: Biology, Pathology and Control, CAB International, Wallingford, p'p. 1-26.

69. Talbot, N.J., Ebbole, D.J., and Hamer, J.E. (1993) Identification and characterization of MPGI, a gene involved in pathogenicity from the rice blast fungus Magnaporthe grisea, Plant Cell 5, 1575-1590.

70. Uchiyama, T., Ogasawara, Y., Nanba, Y., and Ito, H. (1979) Conidial germination and appressorial formation of the plant pathogenic fungi on the coverglass or cellophane coated with various lipid components of plant leaf waxes, Agric. Biol. Chem. 43, 383-384.

71. Van Dyke, C.G. and Mims, C.W. (1991) Ultrastructure of conidia, conidium germination, and appressorium development in the plant pathogenic fungus Colletotrichum truncatum, Can. J. Bot. 69, 2455-2467.

72. Wijesundera, R.L.C., Bailey, J.A., and Byrde, R.J.W. (1984) Production of pectin lyase by Colletoirichum lindemuthianum in culture and in infected bean (Phaseolus vulgaris) tissue, $J$. Gen. Microbiol. 130, 285-290.

73. Wolkow, P.M., Sisler, H.D., and Vigil, E.L. (1983) Effect of inhibitors of melanin biosynthesis on structure and function of appressoria of Colletotrichum lindemuthianum, Physiol. Plant Pathol. 22, $55-$ 71.

74. Wycoff, K.L and Ayres, A.R. (1990) Monoclonal antibodies to surface and extracellular antigens of a fungal plant pathogen, Phytophthora megasperma f.sp. glycinea, recognize specific carbohydrate epitopes, Physiol. Mol. Plant Pathol. 37, 55-79.

75. Xu, J. and Day, A.W. (1992) Multiple forms of fimbriae on the sporidia of com smut, Ustilago maydis, Int. J. Plant Sci. 153, 531-540.

76. Xuei, X., Bhairi, S., Staples, R.C., and Yoder, O.C. (1992) Characterisation of INF 56, a gene expressed during infection structure development of Uromyces appendiculatus, Gene 110, 49-55.

77. Young, D.H. and Kauss, H. (1984) Adhesion of Colletotrichum lindemuthianum spores to Phaseolus vulgaris hypocotyls and to polystyrene, Appl. Environ. Microbiol. 47, 616-619. 